\title{
The evaluation of the damping characteristics of a hard coating on titanium ${ }^{1}$
}

\author{
Christopher Blackwell ${ }^{\mathrm{a}}$, Anthony Palazotto ${ }^{\mathrm{a}, *}$, Tommy J. George ${ }^{\mathrm{b}}$ and Charles J. Cross ${ }^{\mathrm{b}}$ \\ ${ }^{a}$ Department of Aeronautics and Astronautics: Air Force Institute of Technology, 2950 Hobson Way, Building 640, \\ WPAFB, OH 45433-7765, USA \\ ${ }^{\mathrm{b}}$ Air Force Research Laboratory: Propulsion Directorate, 1950 Fifth Street, WPAFB, OH 45433, USA
}

Received 17 November 2005

Revised 7 February 2006

\begin{abstract}
Engine failures due to fatigue have cost the Air Force an estimated $\$ 400$ million dollars per year over the past two decades. Damping treatments capable of reducing the internal stresses of fan and turbine blades to levels where fatigue is less likely to occur have the potential for reducing cost while enhancing reliability. This research evaluates the damping characteristics of magnesium aluminate spinel, $\mathrm{MgO}+\mathrm{Al}_{2} \mathrm{O}_{3}$, (mag spinel) on titanium plates from an experimental point of view. The material and aspect ratio were chosen to approximate the low aspect ratio blades found in military gas turbine fans. In the past, work has generally been performed on cantilever supported beams, and thus the two-dimensional features of damping were lost. In this study plates were tested with a cantilevered boundary condition, using electrodynamic shaker excitation. The effective test area of each specimen was 4.5 in $\times 4.5$ in. The nominal plate thickness was 0.125 in. Mag spinel was applied to both sides of the plate, at a thickness of 0.01 in, and damping tests were run at room temperature. The effect of the coating was evaluated at the 2nd bending mode (mode 3 ) and the chord wise bending mode (mode 4). A scanning laser vibrometer revealed the frequency and shape of each mode for the plates. Sine sweeps were used to characterize the damping of the coated and uncoated specimens for the modes tested. The coating increased damping nonlinearly for both modes tested in which the general outcome was similar to that found in beams.
\end{abstract}

\section{Nomenclature}

$$
\begin{aligned}
& \sigma=\text { stress } \\
& E=\text { Young's modulus } \\
& \varepsilon=\text { strain } \\
& \delta=\text { displacement } \\
& v=\text { velocity } \\
& \omega=\text { frequency (radians/sec) } \\
& \zeta=\text { damping ratio } \\
& \Delta \omega=\text { bandwidth }\left(\omega_{2}-\omega_{1}\right) \\
& \omega_{r}=\text { resonant frequency }
\end{aligned}
$$

\section{Introduction}

It has been shown that a leading cause of failure within a gas turbine engine is related to the blade component's failure after 10000 cycles. This failure is considered as High Cycle Fatigue (HCF). HCF, as opposed to Low Cycle

\footnotetext{
${ }^{1}$ The views expressed in this paper are those of the authors and do not reflect to official policy or position of the United States Air Force, the Department of Defense, or the US Government. This material is declared a work of the US Government and is not subject to copyright protection in the United States.

${ }^{*}$ Corresponding author. E-mail: Anthony.Palazotto@afit.edu.
} 
Fatigue (LCF), has really no actual means of analytically representing its occurrence. The HCF characteristic is evaluated experimentally due to its overall statistical nature. Many references have been published that imply this type of feature [1-4]. In order to mitigate the HCF failure, the aircraft industry has turned to material which can absorb energy and therefore can increase the life of the blades against vibration. This material damps out the blades movement. One material that has shown promise is magnesium aluminate spinel (mag spinel). A discussion of damping and the features of mag spinel can be found in refs [5-10]. Mag spinel is a material that is called hard coating. It also has been found to dampen the blades response over a large range of temperatures and frequencies. It can do this inexpensively and can be easily applied [11-16].

Mag spinel has been studied experimentally for its damping effects and characteristics through beam like response [14,15]. A turbine blade is more associated with a plate, and thus this paper relates to the use of plate geometry and size which represent blades in military gas turbine compressors. The effect of mag spinel to characterize the damping mitigation is experimentally studied to see if the $2 \mathrm{D}$ response in a plate is similar to what is seen in the one dimensional bending characteristics of a beam. Furthermore, over the years it has been shown that the most prevalent modes that cause turbine compressor blade failure is the third (second bending) and fourth (two strip) modes. Thus, these modes are studied in this research.

Mag spinel damping characteristics are highly dependent on both strain within the specimen and mode shape, and because of this the coating produces a nonlinear system damping response. This is attributed to internal friction creating energy dissipation. Thus, part of the study was to determine the effect of the strain levels and mode shapes on the damping response of the structure by mag spinel. The question first addressed was can a linear damping relationship such as a half power-band width technique leading to a coefficient $\mathrm{Q}$ be useful as a decent indicator of damping performance? It was determined that if the following properties exist (based on the findings of Ref. [14]): the maximum strain level experienced by the structure has an upper bound of 500 micro strain, a slow frequency down sweep is followed and there is no so called jump in the frequency response function; then it is acceptable to use the half-band width as a comparison function in order to see damping trends. This is the method incorporated in this paper, and it will be shown that the three properties do exist through out the study.

In order to be complete, a discussion of mag spinel will be included as directed to its composition, technique of application and its damping characteristics.

The usefulness of hard coatings as dampers has been known to engineers since the early 1960's. The damping mechanism was initially assumed to be friction between the particles; which was recently supported experimentally [11-13]. Of particular interest is the air plasma sprayed oxide ceramic coating known as Magnesium Aluminate Spinel (Mag spinel), $\mathrm{MgO}+\mathrm{Al}_{2} \mathrm{O}_{3}$.

The value of mag spinel is that it has a higher damping capacity than other ceramic materials [12]. Magnesium aluminate spinel $\left(\mathrm{MgO}+\mathrm{Al}_{2} \mathrm{O}_{3}\right)$ is an aggregate consisting of $25 \%-28 \% \mathrm{MgO}$, and small amounts of other oxides (e.g. $\mathrm{CaO}, \mathrm{SiO}_{2}, \mathrm{Ma}_{2} \mathrm{O}, \mathrm{Fe}_{2} \mathrm{O}_{3}$ ) and $71 \%-74 \% \mathrm{Al}_{2} \mathrm{O}_{3}$. The density of powders provided for use in erosion/corrosion control is typically given as $3.3 \mathrm{gm} / \mathrm{cm}^{3}$ [14]. Its properties make it useful for erosion resistance against gas streams at elevated temperature; hence, its interest for use in gas turbine engines.

The two most common methods for applying hard coatings are air plasma spraying and physical vapor deposition. The mag spinel for this research was applied by air plasma spraying. Air plasma spray offers advantages in cost, lower application temperatures, and fewer limitations on component size [15]. Plasma spraying provides a denser, stronger coating than most other spray processes. According to APS Materials of Dayton, $\mathrm{OH}$, the high temperature of the plasma allows materials with high melting points to be applied as a coating that cannot be applied by any other means.

Plasma spraying is the process of applying a coating to a substrate material by injecting the coating in a powder form into a high temperature plasma gas and spraying it at high velocity onto the target substrate. The plasma gas (typically air, argon, nitrogen, hydrogen, or helium) converts the powder to a molten state. As the spray impacts the substrate, it cools very quickly, forming a bond with the surface (Fig. 1). When the spray chamber contains the common atmosphere, the process is known as air plasma spraying, which is the most common form of plasma spraying. Occasionally, the atmosphere can provide undesirable contaminants to the coating so the chamber is filled with an inert gas at low pressure. This process is called vacuum spraying.

The main consideration of this paper is to report on the experimental findings directed toward the damping characteristics of mag spinel as a coating attached to a plate. The damping effect of mag spinel on a beam was 


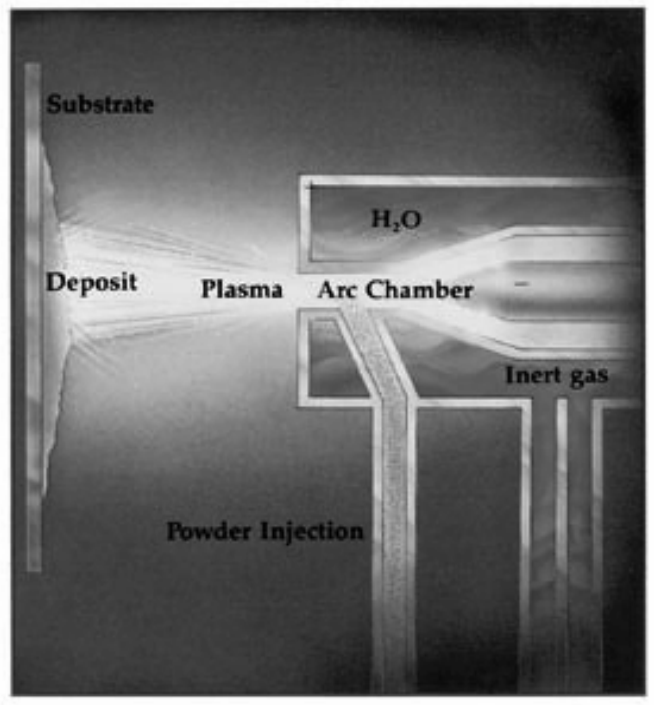

Fig. 1. Schematic of Are plasma spray process (APS Materials, 2004).

found to provide sufficient damping to be effective in reducing vibration amplitudes in aircraft engines [14]. They observed that the response functions were not symmetric about the resonance frequency, and the resonance frequency decreased as the amplitude of the applied force was increased, indicating stiffness non-linearity, or softening. This was also observed in Ref. [5]. The amount of energy dissipated by the coating was shown to be strain dependent. They further concluded that over the first four bending modes, the level of damping obtained was independent of frequency [14]. A question to be considered "Is it possible to extend the approach incorporated in the beam study to a plate's damping evaluation"?

Thus, this investigation compares, from an experimental vibration point of view, the response of titanium plates before and after a mag spinel coating was applied to each side. Titanium plates were tested with a cantilevered boundary condition at the 2 nd bending mode (mode 3 ) and the two stripe, or chord wise bending, mode (mode 4). A three dimensional representation of the first five mode shapes taken from the scanning laser vibrometry tests is shown in Fig. 2. This simulated the cantilevered condition of operational turbine blades and two important mode shapes (see Fig. 3). The vibration excitation was applied through the base and the forcing function is designated in $g$ 's. Strain gages were used to indicate the amount of energy stored and their position and overall relations will be discussed in subsequent paragraphs. The specimens used for this study were 4.5 in $\times 7.0$ in $\times 0.125$ in Ti-6Al-4V plates. The effective test area was 4.5 in $\times 4.5$ in with a 2.0 in clamped region and a 0.5 in tail behind the clamp to help when removing the specimen from the fixture (Fig. 4).

A two piece fixture was designed based on prior Turbine Engine Fatigue Facility (TEFF) experience to increase repeatability. Previous designs could not easily prevent the specimens from shifting in an in-plane direction while under load [16]. This design, which sandwiches the plate between two steel blocks, has eliminated the tendency for the plates to shift by adding two guide shafts through the clamped area of the plate. The top piece slides over the guide shafts and rests on the plate. Four bolts, one through each guide shaft and one beyond both ends of the plate are used to provide the clamping force on the plate (Fig. 3). These shafts also eliminated the variability of the effective plate geometry ( 4.5 in $\times 4.5$ in) from one setup to the next. Without the guide shafts, it would have been necessary to measure the test area before each experiment. A slight difference could influence the repeatability of the experiments. The guide shafts eliminated that problem, and it can be seen from results presented subsequently that repeatability was excellent.

The mag spinel coating was applied to the test area on both sides of the plate by air plasma spray, discussed previously. All damping tests were conducted at room temperature. Damping was characterized by a series of sine sweeps for each of three plates before and after the mag spinel was applied. The excitation load was increased for 

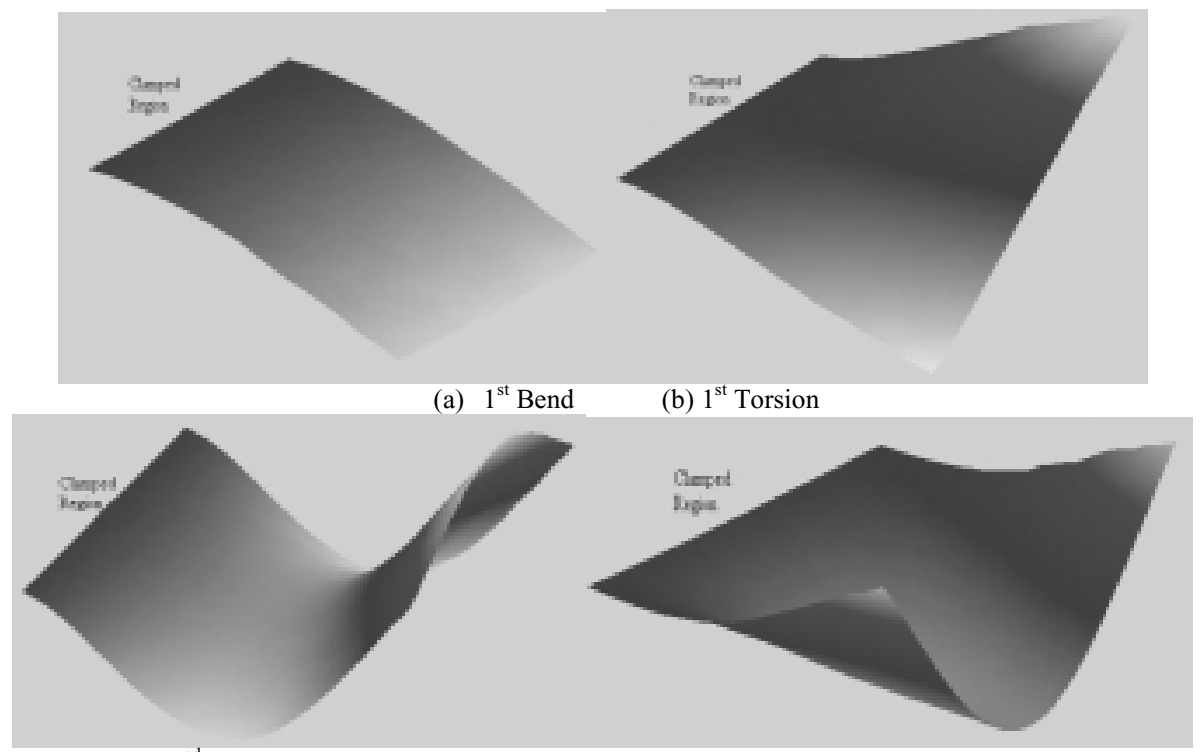

(c) $2^{\text {nd }}$ Bend

(d) Chordwise

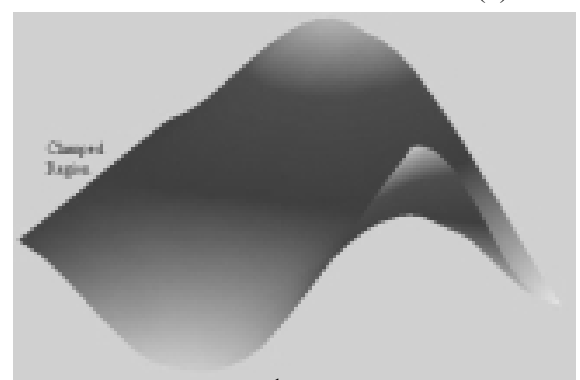

(e) $2^{\text {nd }}$ Torsion

Fig. 2. First five plate modes.

each successive sweep. The "half-power bandwidth" method was used, as previously indicated, to determine the level of damping for each sine sweep and comparisons were made between the coated and uncoated configurations. Test specimens were characterized by frequency, mode shape, damping, and stress pattern. Testing was conducted at the Turbine Engine Fatigue Facility, AFRL/PRTS, Wright-Patterson AFB, OH.

A scanning laser vibrometer measured the frequency for each mode and the eigenvector contour of the plate. These contours were compared with NASTRAN Version 2001.0.1 FEM models, which were used to determine the stress ratio for the stress at the strain gage location (discussed in Section 3: Test Setup and Procedures) to the maximum stress for the two resonant modes under consideration. Stress and strain are related through Hooke's Law and, as will be pointed out later on, the strain gages were positioned at locations where only one dimensional strain occurred.

$$
\sigma=E \varepsilon
$$

The finite element method (FEM) was used to associate the resonant frequencies, mode shapes, and stress ratios for the uncoated plates. Sine sweeps with strain gages attached were used to develop the strain/displacement relationship by comparing the peak laser vibrometer velocity response to the peak strain gage response. It should be noted that, as shown in Fig. 4, two strain gages were positioned at the points of maximum strain for the respective modes three and four, and one velocity plate point was traced with respect to time. Therefore, it was necessary to construct a velocity-strain function. This approach is part of the next section. Furthermore, it should be pointed out that since strain gages will add some damping to the system, it was necessary to record velocity - strain data before strain gages were removed, and thus allowing any coated conditions at maximum strain points to be recorded without attached 


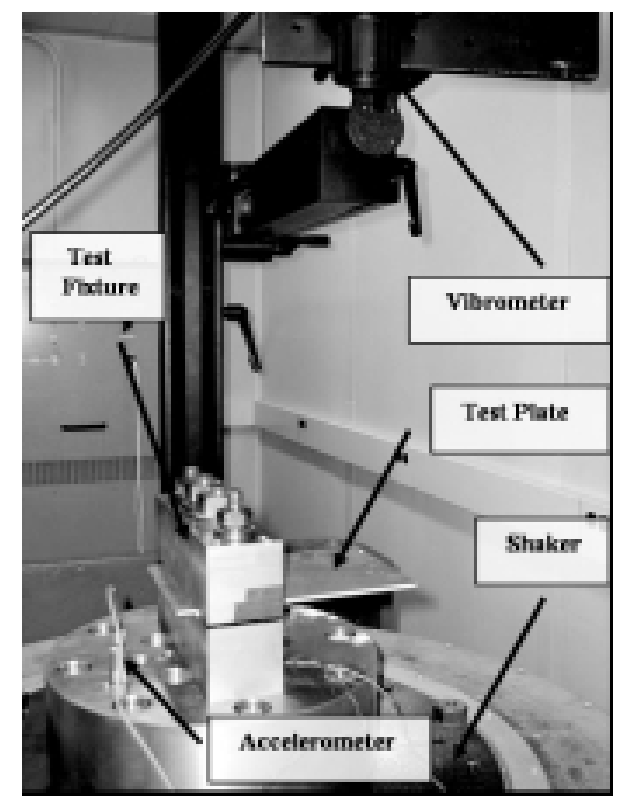

Fig. 3. Shaker table setup.

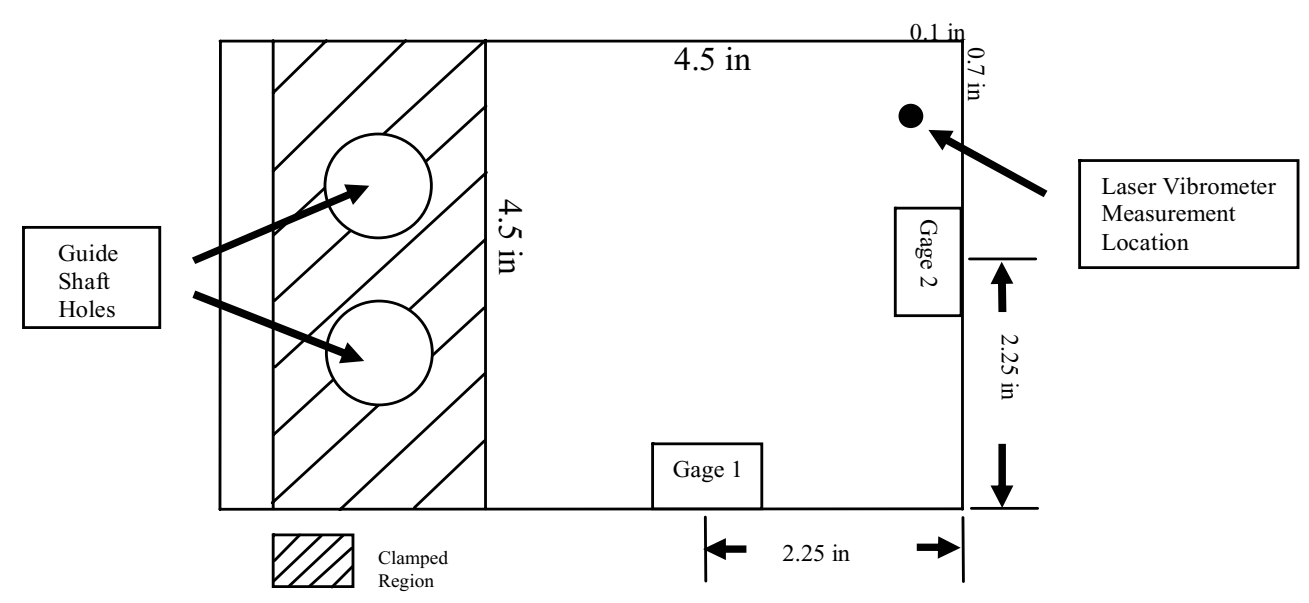

Fig. 4. Laser vibrometer measurement location.

gages. Damping ratios, for several strains up to a maximum of 500 micro-strain, were determined by conducting sine sweeps on a 6,000 lb electro-dynamic shaker and measuring the plate's dynamic response with a single point laser vibrometer. The purpose of this research was to focus on the damping characteristics of mag spinel at low strains; therefore 500 micro-strain was chosen as the upper limit. The same titanium plates were compared before and after the mag spinel coating was applied.

\section{Prediction method}

Finite element modeling was performed using NASTRAN version 2001.0.1 to determine the natural frequencies and mode shapes of the uncoated plates. The nominal plate dimensions of 4.5 in $\times 4.5$ in $\times 0.125$ in were used. Three different mesh densities consisting of 256, 529, and 900 QUAD4 elements, were used to satisfy convergence of the finite model to a continuous system. The solution algorithm used the Lanczos method to solve the eigenvalue 
Table 1

Theoretical and Experimental Mode 3 Natural Frequencies (Hz) for the Uncoated Plates w/out Strain Gages

\begin{tabular}{lcccc}
\hline MODE 3 $(\mathrm{Hz})$ & Theoretical Prediction & Finite Element Method & Scanning Laser Vibrometer & Sine Sweep \\
\hline Plate T1 & 1257 & 1244.8 & 1247.7 & 1245.8 \\
Plate T2 & 1257 & 1244.8 & 1259.8 & 1255.0 \\
Plate T3 & 1257 & 1244.8 & 1263.3 & 1257.1 \\
\hline
\end{tabular}

Table 2

Theoretical and Experimental Mode 4 Natural Frequencies (Hz) for the Uncoated Plates w/out Strain Gages

\begin{tabular}{lcccc}
\hline MODE 4 $(\mathrm{Hz})$ & Theoretical Prediction & Finite Element Method & Scanning Laser Vibrometer & Sine Sweep \\
\hline Plate T1 & 1610 & 1587.6 & 1618.1 & 1614.5 \\
Plate T2 & 1610 & 1587.6 & 1634.8 & 1632.1 \\
Plate T3 & 1610 & 1587.6 & 1639.4 & 1635.3 \\
\hline
\end{tabular}

(natural frequency) problem. For a detailed discussion of this solution method see Ref. [17]. For this geometry, all the nodes along one edge of the plate were constrained in all six degrees of freedom to represent a cantilevered condition and all other nodes were unconstrained. The material properties were obtained from MIL-HDBK-5CD-ROM, May 1997 for Ti-6Al-4V (Young's Modulus $=1.6^{*} 10^{\wedge} 7 \mathrm{psi}$, Poisson's Ratio $=0.31$, and Yield Stress $=126 \mathrm{ksi}$ ). As the mesh density was increased, the frequency results converged to a single value. A comparison to analytic predictions verified the accuracy of the finite element model. A 256 element model and analytic equation for plates [18], have very good agreement as shown in Tables 1 and 2. As the number of elements used in the model increases, agreement with the prediction improved.

It was possible to obtain, from the finite element solution, the ratio of the displacement or stress at one point, usually the maximum location of either, to any other point on the plate. The second point is usually where the strain gage is placed. Using this ratio, the maximum stress was known during experiments, even if the strain gage is not located at the point of maximum stress. Hooke's law, Eq. (1), was used to relate the stresses to strains. It should be noted that the strain gage was placed parallel with the free edge of the plate, and thus the strain was being read at coordinates in which one-dimensional strain occurred. The use of this approach is further elaborated upon in the Test Setup and Procedure section.

\section{Test setup and procedures}

\subsection{Data collection}

Because of the non-linear characteristics of mag spinel, the strain-dependent effect must be considered. Previous work showed that when sine-sweep data from various strains or amplitudes are overlapped, the resonant peaks cannot be connected via a straight line [16] (See the physical evidence of this phenomenon in Sections 4-5 Damping). It will be seen that for the uncoated plates the peak resonant frequency is very nearly constant as the load is increased, but for the coated plates the peak frequency moves nonlinearly down the frequency spectrum as the load is increased. This is known as strain softening. The strain softening effect requires that the sweep be done from high to low frequency; otherwise the peak may be missed.

\subsection{Strain gages}

Two strain gages, of type CEA-05-062UW-350, were placed on each plate. Based on the scanning laser vibrometry results in conjunction with the finite element solutions, presented in Section 5, gage one, for mode 3, was placed on the edge 2.25 in from the tip on the side perpendicular to the clamp and gage two, for mode 4, was placed on the edge 2.25 in from the tip on the free edge parallel to the clamp (Fig. 4). A study was carried out to see the effect of the strain gages on frequency response. This was measured using the scanning laser vibrometer in the process of determining the plate's natural frequency. Because the gages may add damping to the plates and because they cannot be glued to the mag spinel coating without changing its properties, damping measurements were not made with strain gages attached. The strain gages were only used on the uncoated plates to establish the strain/displacement relationship. 
Table 3

Resonant frequencies from laser vibrometer test for plate T1 (Uncoated without strain Gages)

\begin{tabular}{lcccc}
\hline Plate T1 $(\mathrm{Hz})$ & Uncoated (Run 1) & Uncoated (Run 2) & Average & \% Diff \\
\hline Mode 1 & 205.63 & 205.31 & 205.47 & 0.15 \\
Mode 2 & 490.31 & 490.00 & 490.16 & 0.06 \\
Mode 3 & 1248.13 & 1247.19 & 1247.66 & 0.08 \\
Mode 4 & 1618.13 & 1618.13 & 1618.13 & 0.00 \\
Mode 5 & 1791.56 & 1790.94 & 1791.25 & 0.03 \\
\hline
\end{tabular}

Plate T1: Average Spectrum Comparison

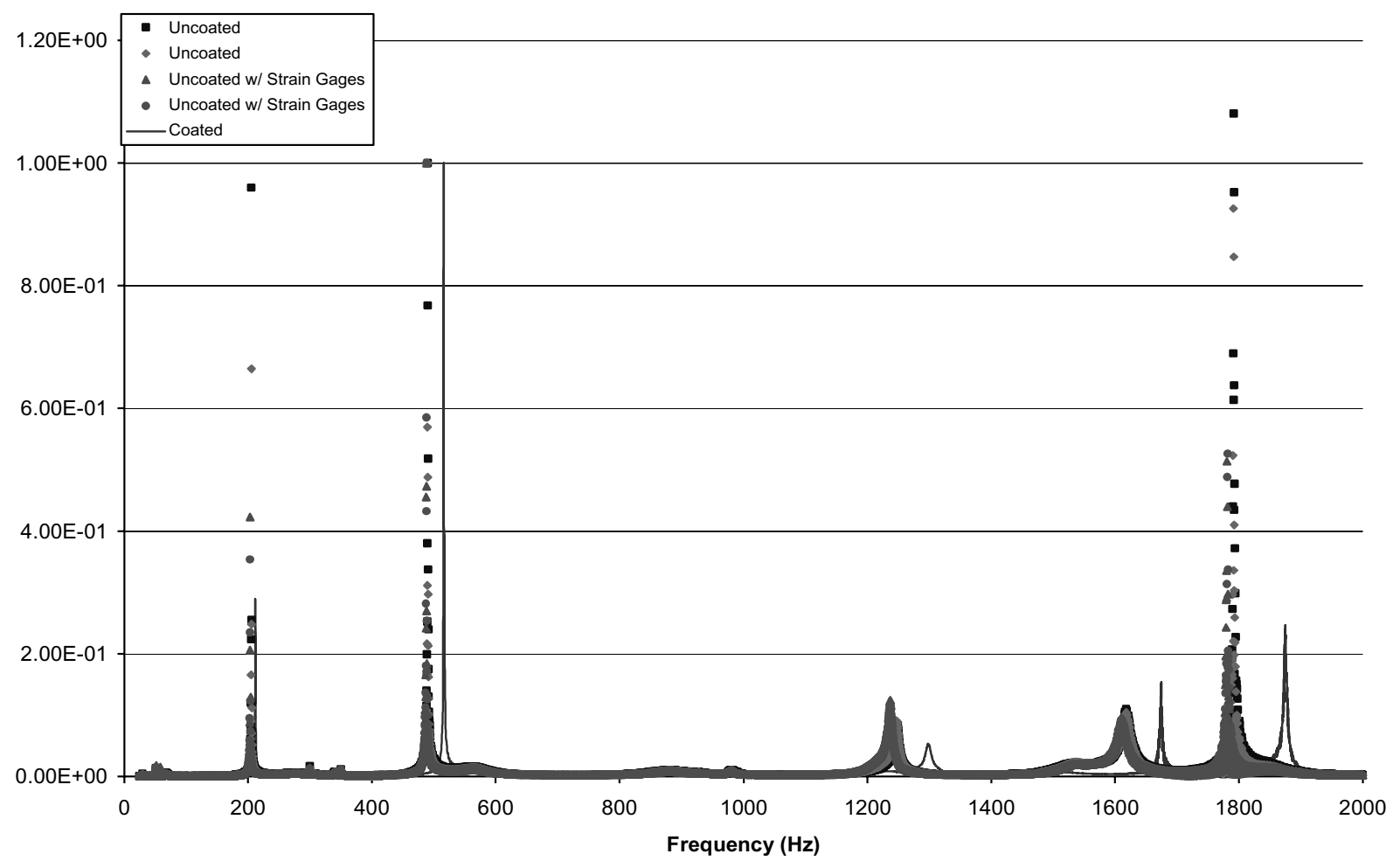

Fig. 5. Frequency response from laser vibrometer for plate T1. (Uncoated with and without strain gages and coated).

\subsection{Modal characterization}

Three plates were tested with each possible configuration: uncoated without strain gages, uncoated with strain gages, and coated. Each plate was held using the mounting fixture designed for the sine sweeps. The torque on the two bolts that pass through the guide shafts was $125 \mathrm{ft}-\mathrm{lbs}$ and the torque on the two outer bolts was $100 \mathrm{ft}-\mathrm{lbs}$. The guide shaft bolts were set at a higher torque because they were directly above the plate and provided most of the clamping force. The fixture was then placed in a vise bolted to the table, which was floated to prevent outside vibrations from interfering with the experiment. An air horn placed at the free end corner provided the excitation source (test set-up not shown). Sweeps were done between 0-2 kHz, which captured the first five resonant modes and displacement shapes. These shapes can be compared directly to the FEM modal results. The controller was set to take data points at every $312.5 \mathrm{MHz}$, which provided very high resolution output.

\subsection{Strain-velocity-displacement calibration}

A laser, mounted to a rigid support, was used to measure the plate velocity at a single point. The target point was near one of the free corners opposite the clamped section, 0.1 in from the free edge and 0.7 in from the side (Fig. 4). 
Table 4

Resonant frequencies from laser vibrometer for plate $\mathrm{T} 1$ (Uncoated with and without strain Gages)

\begin{tabular}{lrcc}
\hline $\begin{array}{l}\text { Plate T1 } \\
(\mathrm{Hz})\end{array}$ & $\begin{array}{c}\text { Uncoated } \\
\text { Average }\end{array}$ & $\begin{array}{c}\text { Uncoated w/Strain } \\
\text { Gages Average }\end{array}$ & $\begin{array}{c}\text { \% Diff of } \\
\text { Averages }\end{array}$ \\
\hline Mode 1 & 205.47 & 203.44 & 0.99 \\
Mode 2 & 490.16 & 487.97 & 0.45 \\
Mode 3 & 1247.66 & 1237.19 & 0.84 \\
Mode 4 & 1618.13 & 1611.25 & 0.43 \\
Mode 5 & 1791.25 & 1781.26 & 0.56 \\
\hline
\end{tabular}

Plate T3: Uncoated with Strain Gages

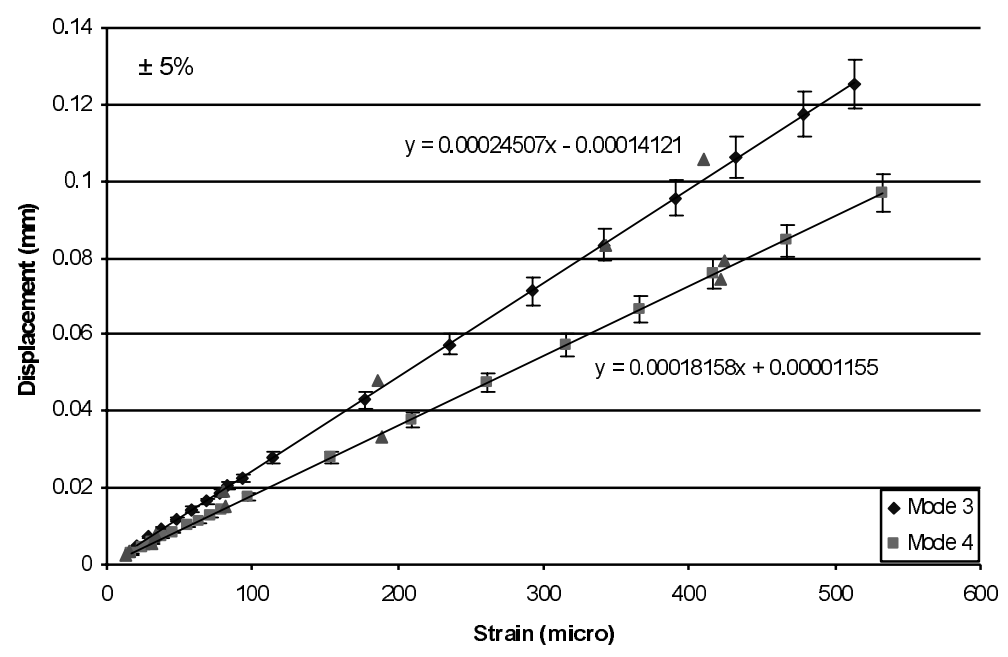

Fig. 6. Strain/Displacement relationship for plate T3.

The laser controller was not configured to take displacement measurements; therefore velocities were measured and converted to displacements, and it was the displacement that was related to the maximum strain for each mode. The velocity for maximum strain at this position for both modes was such that the laser controller would not have to be changed between mode testing. An accelerometer was placed at the base of the shaker to record the input load. It is acceptable to equate a change in acceleration as the equivalent change in applied force because the mass of the system is not changing and force changes linearly with acceleration. VibrationVIEW software, version 4.0.17, was used to control the data acquisition. The resonant frequency for each mode, determined from the modal characterization test, was swept through at a rate of $5 \mathrm{~Hz} / \mathrm{min}$. The peaks from the laser and the appropriate strain gage establish the strain/velocity relationship at that excitation load. This process was repeated up to twenty times for each plate as the load was increased to create a complete strain/velocity curve. The strain/velocity relationship was determined for each mode and plate through a plot as shown in Section 4.2. Since strain is a function of displacement, the velocity measurements were converted to displacements. Maximum displacement is correlated using the following relationship:

$$
\delta=\frac{\nu}{\omega}
$$

Since strain gages were not applied directly to the mag spinel, velocity was the only measurement available. An equivalent displacement from the coated plates results in the same strain at the plate coating interface. Since the coating increases the damping of the plate, it is expected that a greater applied load will be required to produce the same displacement as for the uncoated plate. 


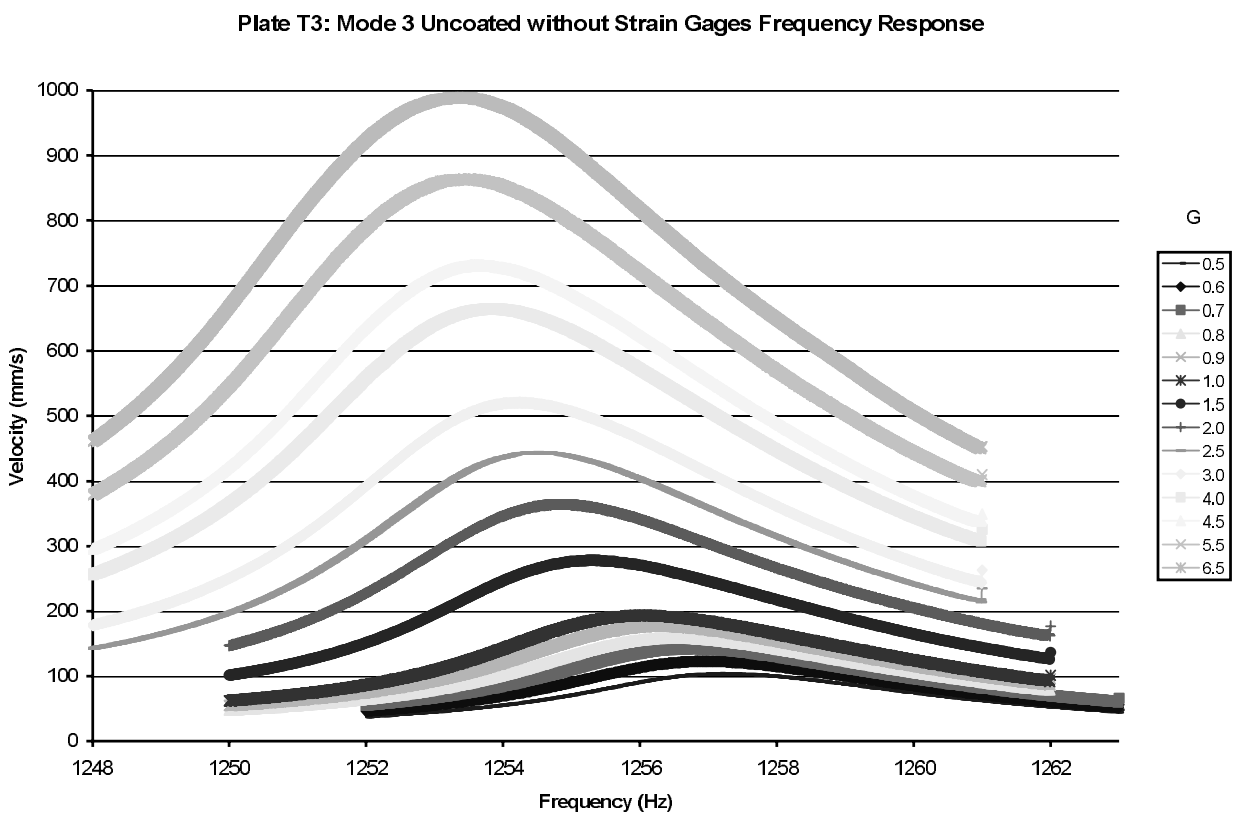

Plate T3: Mode 3 Coated Frequency Response

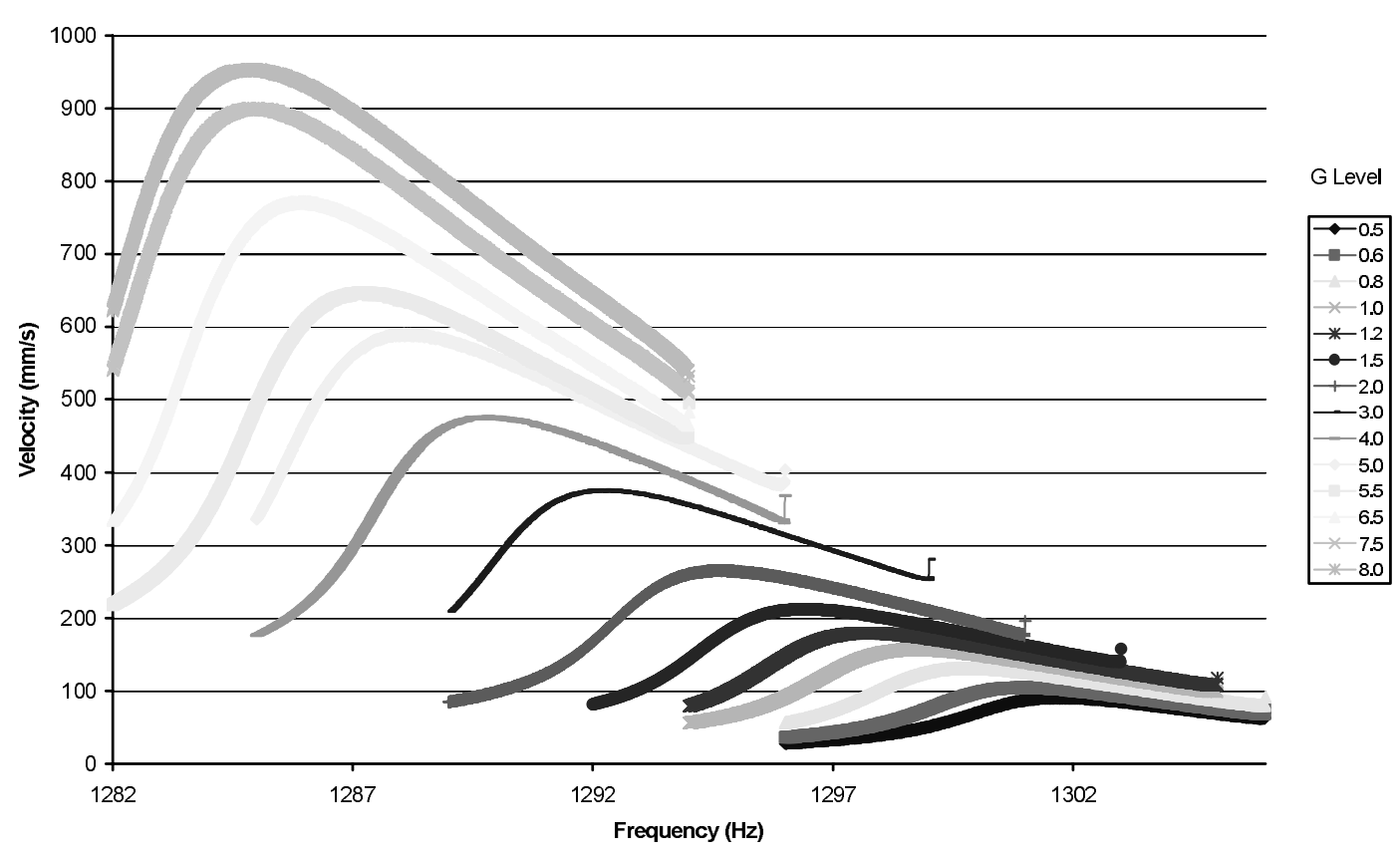

Fig. 7. Sine sweeps for plate T3: Mode 3 Uncoated and coated.

\subsection{Damping characterization}

Sine sweeps were used to first determine the resonant frequencies and the sweeps were incorporated in representing the level of damping as a function of the maximum strain. The sweeps were conducted on a 6,000 lb shaker using Unholtz-Dickie VWIN software; version 4.74 An accelerometer was placed at the base of the shaker to record the input acceleration. The damping levels of the uncoated plates without strain gages were established to provide a 


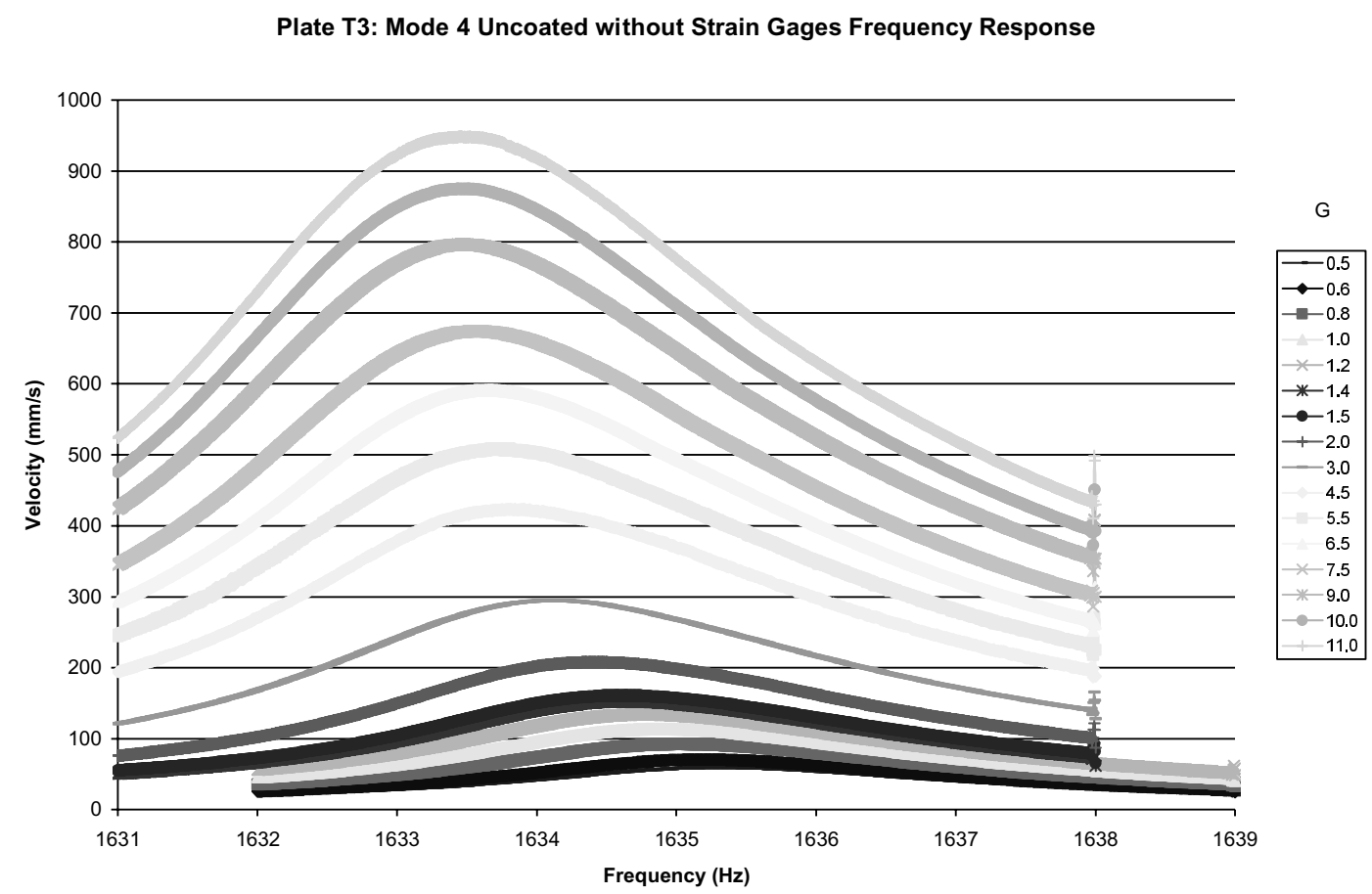

Plate T3: Mode 4 Coated Frequency Response

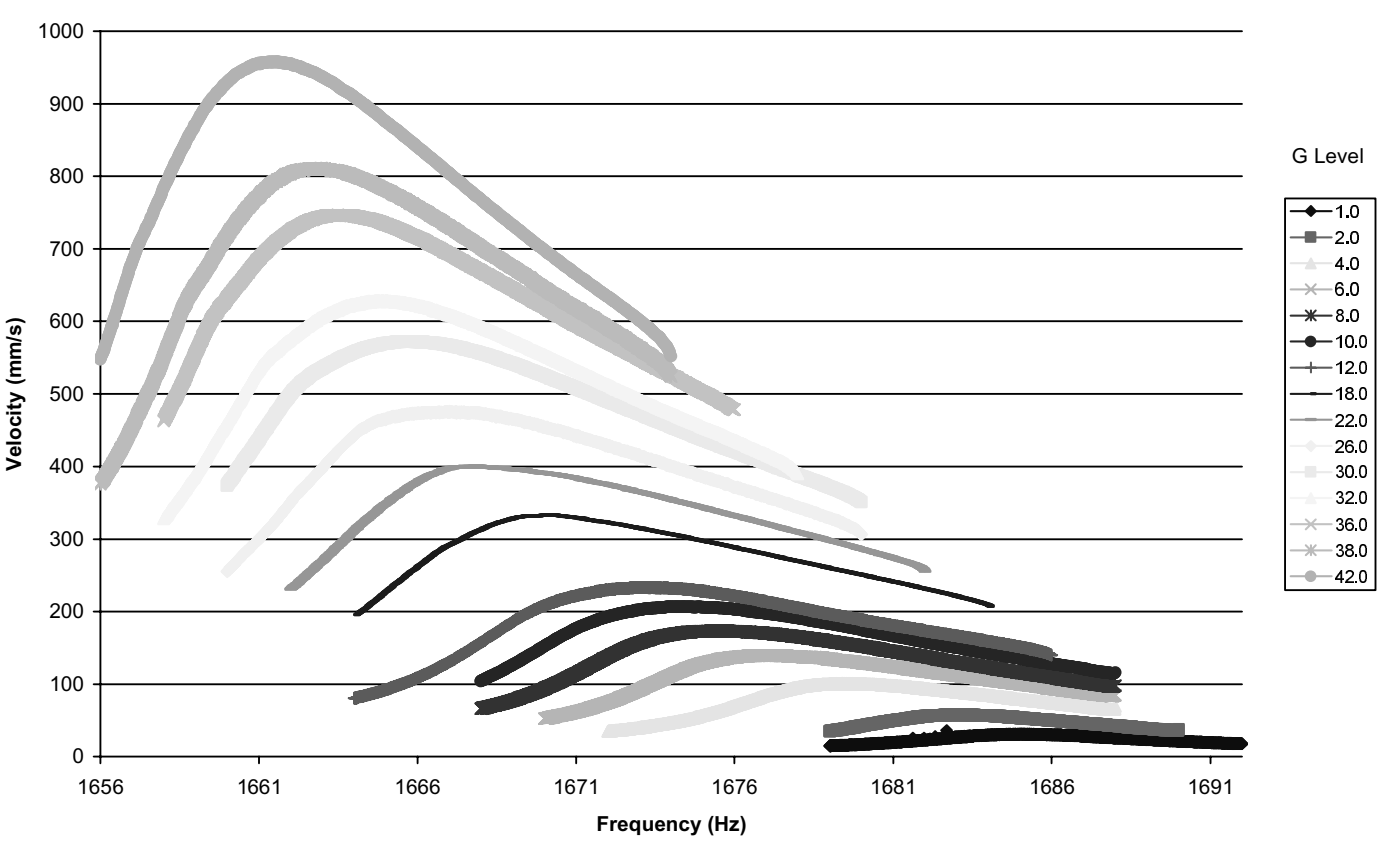

Fig. 8. Sine sweeps for plate T3: Mode 4: Uncoated and coated.

baseline for determining the damping levels provided by the mag spinel coating. Velocities of the target points, referenced to previously, were measured at this location for both modes -2 nd bend and chord wise bend - and converted to strain using the strain/displacement curves. 


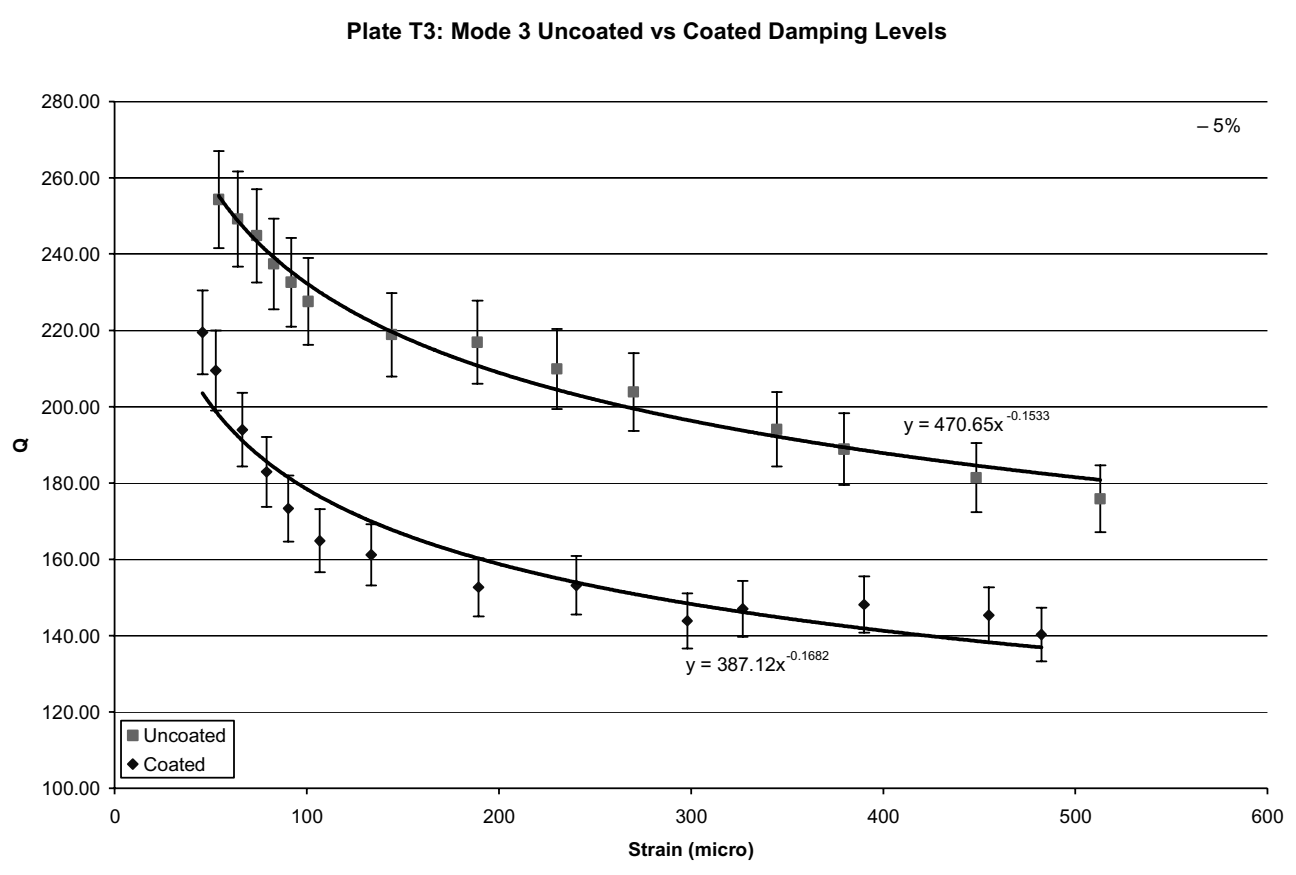

Plate T3: Mode 4 Uncoated vs Coated Damping Levels

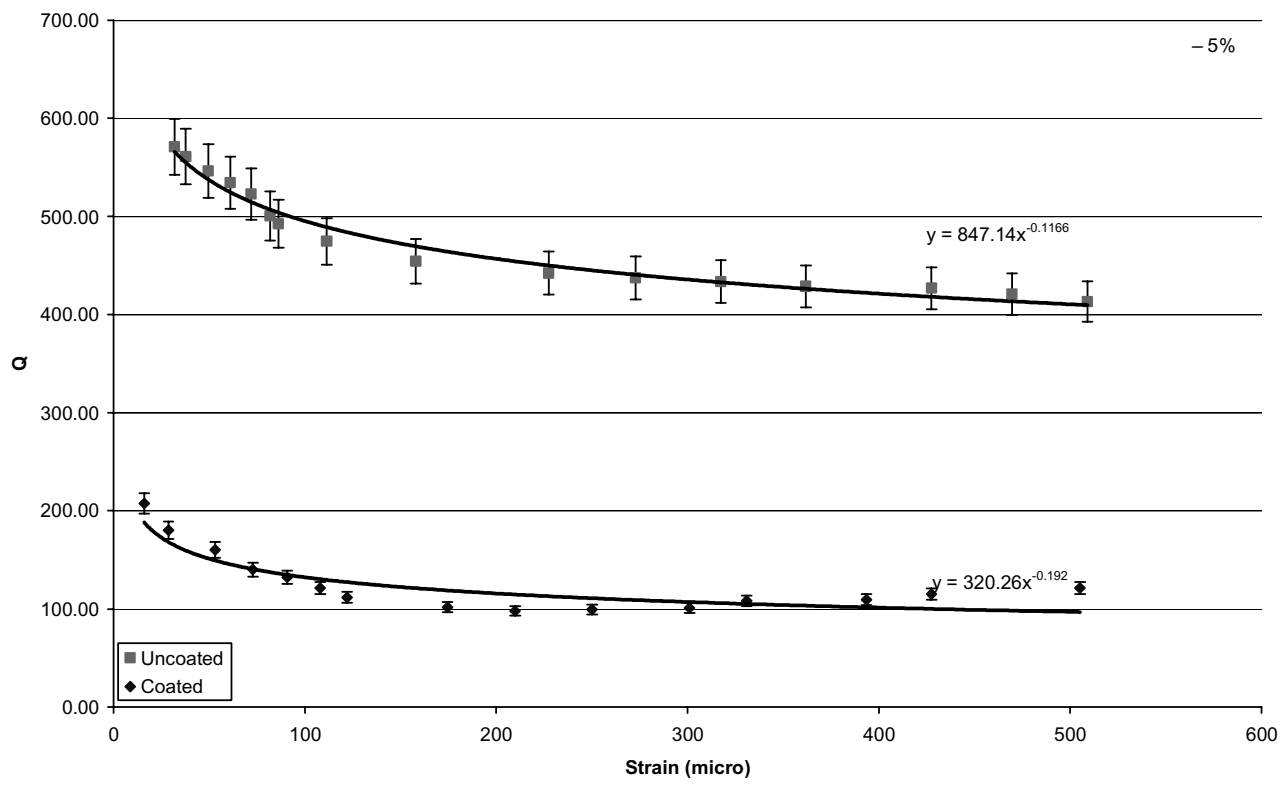

Fig. 9. Q-Strain relationship for plate T3: Uncoated and coated.

The frequency range for each sine sweep was broad enough to capture response levels of $70 \%$ of the peak value. This provides sufficient data to perform the "half-power bandwidth" calculation, discussed later in this section. Each sweep was done at $5 \mathrm{~Hz} / \mathrm{min}$ to ensure the peak was not missed. If the sweeps are made too quickly then the response does not have enough time to rise to the true peak amplitude. This is due to the fact that the frequency is constantly being altered, and a transient response is constantly being excited. By limiting the sweep rate, the transient responses have an opportunity to decay leaving only the force response. Six to ten different input accelerations representing 
Table 5

Uncoated versus coated Q comparison at different strains for plate T3

\begin{tabular}{ccccccc}
\hline $\begin{array}{c}\text { Plate T3 } \\
\text { Strain }\end{array}$ & $\begin{array}{c}\text { Mode 3 } \\
\text { Uncoated Q }\end{array}$ & $\begin{array}{c}\text { Mode 3 } \\
\text { Coated Q }\end{array}$ & $\begin{array}{c}\text { Mode 3 } \\
\text { \% Diff }\end{array}$ & $\begin{array}{c}\text { Mode 4 } \\
\text { Uncoated Q }\end{array}$ & $\begin{array}{c}\text { Mode 4 } \\
\text { Coated Q }\end{array}$ & $\begin{array}{c}\text { Mode 4 } \\
\text { \% Diff }\end{array}$ \\
\hline 10 & 330.67 & 262.81 & 20.52 & 647.67 & 205.83 & 68.22 \\
20 & 297.34 & 233.89 & 21.34 & 597.39 & 180.18 & 69.84 \\
30 & 279.42 & 218.47 & 21.81 & 569.80 & 166.68 & 70.75 \\
40 & 267.36 & 208.15 & 22.15 & 551.00 & 157.73 & 71.37 \\
50 & 258.37 & 200.48 & 22.41 & 536.85 & 151.11 & 71.85 \\
60 & 251.25 & 194.43 & 22.62 & 525.56 & 145.91 & 72.24 \\
70 & 245.38 & 189.45 & 22.79 & 516.20 & 141.66 & 72.56 \\
80 & 240.41 & 185.24 & 22.95 & 508.22 & 138.07 & 72.83 \\
90 & 236.11 & 181.61 & 23.08 & 501.29 & 134.99 & 73.07 \\
100 & 232.33 & 178.42 & 23.20 & 495.17 & 132.28 & 73.29 \\
150 & 218.32 & 166.66 & 23.66 & 472.31 & 122.38 & 74.09 \\
200 & 208.91 & 158.79 & 23.99 & 456.73 & 115.80 & 74.65 \\
250 & 201.88 & 152.94 & 24.24 & 445.00 & 110.94 & 75.07 \\
300 & 196.32 & 148.32 & 24.45 & 435.64 & 107.13 & 75.41 \\
350 & 191.73 & 144.52 & 24.62 & 427.87 & 104.00 & 75.69 \\
400 & 187.85 & 141.31 & 24.77 & 421.26 & 101.37 & 75.94 \\
450 & 184.48 & 138.54 & 24.90 & 415.52 & 99.10 & 76.15 \\
500 & 181.53 & 136.11 & 25.02 & 410.45 & 97.12 & 76.34 \\
\hline
\end{tabular}

a range of 10-100 maximum micro-strains and another six to eight representing a range of 100-500 maximum micro-strains were tested. The VWIN software takes the excitation signal and the plate response signal and conducts a fast Fourier transform to convert the data to the frequency domain. The output is an amplitude (velocity) versus frequency graph, where each peak represents a resonant frequency and mode.

Damping was determined by the "half-power bandwidth" calculation. The half-power is calculated by measuring the bandwidth of the frequency curve (or approximately $3 \mathrm{~dB}$ ) down from the resonant peak

The damping ratio is then found using Eq. (3):

$$
\zeta=\frac{\Delta \omega}{2 \omega_{r}}
$$

A parameter commonly used in the damping community is the quality factor $(\mathrm{Q})$. The quality factor was developed by electrical engineers as a measure of the clarity of an electrical signal. The quality factor and damping ratio are inversely proportional.

$$
Q=\frac{1}{2 \zeta}(\operatorname{Ref} 19)
$$

The VWIN software has the capability of determining the quality factor by this method. It can be seen from Eq. (4) that as damping $(\zeta)$ increases, Q decreases. Therefore, a good damping material will dissipate more energy and have a lower $\mathrm{Q}$ value.

\section{Results and discussion}

\subsection{Resonant frequencies}

Resonant frequencies were experimentally determined for each of three plates from sine sweeps and laser vibrometry for both the uncoated and coated plates. The resonant frequencies were determined from the peaks on a frequency response curve. Predictions were also made using the finite element modeling.

\subsubsection{Comparison to theoretical predictions}

Comparisons of the resonant frequencies between finite element predictions and experimental results could only be made with the uncoated plates. If a good correlation exists between the theoretical and experimental results, the finite element model can be used as a benchmark for comparison of experimental values. The modes of interest 
Table 6

Average uncoated versus average coated Q comparison at different strains

\begin{tabular}{ccccccc}
\hline $\begin{array}{c}\text { Mode 3 } \\
\text { Strain }\end{array}$ & $\begin{array}{c}\text { Mode 3 } \\
\text { Average Uncoated Q }\end{array}$ & $\begin{array}{c}\text { Mode 3 } \\
\text { Average Coated Q }\end{array}$ & $\begin{array}{c}\text { Mode 4 } \\
\text { \% Diff }\end{array}$ & $\begin{array}{c}\text { Mode 4 } \\
\text { Average Uncoated Q }\end{array}$ & $\begin{array}{c}\text { Mode 4 } \\
\text { Average Coated Q }\end{array}$ & $\begin{array}{c}\text { \% Diff } \\
10\end{array}$ \\
\hline 307.86 & 258.28 & 16.10 & 696.09 & 62.72 \\
30 & 282.05 & 228.61 & 18.95 & 644.53 & 208.06 & 67.72 \\
40 & 268.02 & 212.86 & 20.58 & 616.17 & 183.42 & 70.23 \\
50 & 258.52 & 202.36 & 21.72 & 596.81 & 167.97 & 71.86 \\
60 & 251.39 & 194.57 & 22.60 & 582.21 & 157.01 & 73.03 \\
70 & 245.72 & 188.43 & 23.31 & 570.55 & 148.67 & 73.94 \\
80 & 241.03 & 183.40 & 23.91 & 560.88 & 136.53 & 74.68 \\
90 & 237.05 & 179.14 & 24.43 & 552.63 & 131.89 & 75.82 \\
100 & 233.59 & 175.47 & 24.88 & 545.46 & 127.90 & 76.28 \\
150 & 230.54 & 172.25 & 25.28 & 539.12 & 113.77 & 77.93 \\
200 & 219.20 & 160.41 & 26.82 & 515.41 & 94.84 & 79.00 \\
250 & 211.51 & 152.51 & 27.90 & 499.23 & 98.47 & 79.78 \\
300 & 205.75 & 146.65 & 28.72 & 487.03 & 93.60 & 80.39 \\
350 & 201.16 & 142.03 & 29.39 & 477.28 & 89.70 & 80.88 \\
400 & 197.36 & 138.24 & 29.96 & 469.19 & 86.47 & 81.30 \\
450 & 194.14 & 135.04 & 30.44 & 462.30 & 83.73 & 81.65 \\
500 & 191.34 & 132.28 & 30.87 & 456.30 & 81.36 & 81.96 \\
\hline
\end{tabular}

for this research as stated previously were, modes 3 and 4, and are compared in Tables 1 and 2, respectively. The finite element model prediction is within $1.5 \%$ of the experimental results for mode 3 and within $3.3 \%$ for mode 4. Therefore, the finite element model closely approximates reality. Because the measured frequencies are so very close to the theoretical predictions, it can be assumed the test fixture provided a very rigid boundary condition. A loose fixture would have resulted in measured frequencies much lower than predicted.

\subsubsection{Experimental resonant frequencies}

All three plate conditions; uncoated without strain gages, uncoated with strain gages, and coated, were tested for frequency response between $0-2 \mathrm{kHz}$ for all three plates using the scanning laser vibrometer. Five resonant frequencies can be identified within this range for each plate. As stated earlier for this part of the study, an air horn was incorporated to actuate the plate and the excitation load from the air horn was not measured. Therefore, just the location of the peak frequencies are shown in Fig. 5 and compared for the different plate configurations and not the amplitudes. Resultant strain levels do not exceed 2 micro-strains for either mode 3 or 4 due to strain gage readings. Configuration effects and repeatability were compared by repeating sine sweeps for the uncoated plates, with and without strain gages, and again when the plates were coated. It was seen that repeatability was excellent, see Table 3 as an example of this. The effect on frequency response due to the strain gages was another area of interest. It can be seen from Table 4 that there was no significant influence to frequency response from the strain gages. The mag spinel coating caused a small increase in the resonant frequencies, with no more than $5.2 \%$ difference. This increase was expected based on the increased plate thickness from the mag spinel coating.

\subsection{Strain/displacement relationship}

In the next part of the investigation, the establishment of the strain/displacement relationship with the single-point laser vibrometer was necessary because damping measurements were to be conducted on the plates without strain gages. However, comparisons of damping based on strain rather than velocity were desired. Because strain gages would not be attached to the mag spinel coating they should also not be included in the baseline uncoated damping measurements, but a set of runs had to be correlated with the strain gage readings. To determine this relationship, the velocity and strain at resonance were measured for each mode by conducting up to twenty slow $(5 \mathrm{~Hz} / \mathrm{min})$ sine sweeps, with an increased excitation load for each sweep. The details of the test setup are discussed in Section 3. 500 micro-strain was the upper limit for this research. Since strain is proportional to displacement and not velocity, the velocity measurements had to be converted to displacements. As indicated previously, this is done by dividing the velocity at peak resonance by the peak resonance frequency. Because there is very little shift in the resonant 
frequency from low to high load for the uncoated plate this step may seem unimportant. However, the strain softening effect of the mag spinel coating causes a noticeable shift in resonant frequency as excitation loads are increased and thus the frequency influence is more pronounced. The strain/displacement relationship for plate \#3 can be seen in Fig. 6. Strains for both modes are reported at the maximum strain location. Error bars $( \pm 5 \%)$ are plotted to show the level of agreement each data point has with the trend line. The equations of the trend lines are used to convert displacements to strains.

\subsection{Damping}

Damping characterization was conducted by a series of sine sweeps on the uncoated and coated plate configurations and is reported for plate T3. The sweeps were made using a 6,000 lb shaker. Results of the sweeps are shown in Figs 7 and 8 . The non-linearity is immediately apparent when comparing the uncoated sweeps to the coated sweeps. The peaks for each sweep were fairly frequency stable as the load increased (reflected through the $G$ values), for the uncoated plates, but the peaks for the coated plates decreased by as much as $25 \mathrm{~Hz}$ as the load was increased. This phenomenon is known as strain softening (notice the curves do not reflect any frequency jump which according to [14] allows Q to be used as a damping characterizing parameter). The small frequency decrease, less than $5 \mathrm{~Hz}$, for the uncoated plates may be attributed to a less than perfect boundary condition at the fixture. For a perfectly linear system with a perfect boundary condition the peaks would occur at the same frequency for all loads. Another observation is the increased load needed for the coated plate to produce a sweep with an equivalent velocity to the uncoated plate. This is a legitimate method for quantifying Q, but it says nothing about the strain levels and is therefore not used in this paper.

As was expected, the mag spinel coating caused an increase in damping; even at very low strain levels. The non-linear relationship between $\mathrm{Q}$ and strain is plotted in Fig. 9. A best fit curve was applied to the experimental results and error bars of $5 \%$ were added to each data point to provide a perspective of how well the data fits the trend line (there is no correlation to any predicted precision of the measurements). The Q's show a rapid decrease, increased damping, up to about 100 micro-strain for both modes. The decreasing trend continues beyond 100 micro-strain for mode 3 but it levels off for mode 4 . From the best fit curves, the predicted improvements in damping over the uncoated plates were calculated for selected strains. The results are presented in Table 5 for plate T3. The average increase in damping across all three plates is presented in Table 6. Mode 4 was tested first for each plate, with the first sweep at the high strain point and the last sweep at the low strain point. The same process was then repeated for mode 3. Repeat strain points for both modes were measured in the same manner (high strain to low strain) and recorded after the sweeps for both modes were complete.

At 10 micro-strain the difference in Q for mode 3 is $16 \%$ and for mode 4 is $63 \%$. At 100 micro-strain the difference in Q for mode 3 is $25 \%$ and for mode 4 is $76 \%$. At 500 micro-strain the difference in Q for mode 3 is $31 \%$ and for mode 4 is $82 \%$.

\section{Conclusion}

Strain softening was seen in the frequency response when the mag spinel was applied. The peaks for each sweep were fairly stable as the load was increased for the uncoated plates, but the peaks for the coated plates decreased by as much as $25 \mathrm{~Hz}$ as the load increased. The small frequency decrease, less than $5 \mathrm{~Hz}$, for the uncoated plates may be attributed to a less than perfect boundary condition at the fixture. For a perfectly linear system with a perfect boundary condition, the peaks would occur at the same frequency for all loads.

As compared to beam experiments, the mag spinel coating caused an increase in damping; even at very low strain levels. For all three plates, damping appears to be a function of mode shape. The Q's show a rapid decrease, increased damping, up to about 100 micro-strain for both modes. The decreasing trend continues beyond 100 micro-strain for mode 3 but it levels off for mode 4 .

The average increase in damping at 10 micro-strain for mode 3 is $16 \%$ and for mode 4 is $63 \%$. At 100 micro-strain the average increase in damping due to the mag spinel coating for mode 3 is $25 \%$ and for mode 4 is $76 \%$. At 500 micro-strain the average increase in damping for mode 3 is $31 \%$ and for mode 4 is $82 \%$. Therefore, showing the damping effect is greatly dependent upon mode shape characteristics. Thus, since the plate is a good representation of a turbine blade, one can use the results obtained in this research to characterize mag spinel's effect as a damping material in an actual turbine engine. 


\section{Acknowledgments}

The authors would like to thank the Air Force Research Laboratory, Turbine Engine Division: Structures and Controls Branch for the use of their facility, financial assistance, and expert guidance.

\section{References}

[1] J. Grady, Fundamentals of high-cycle fatigue, Machine Design 71(18) (1999), 86.

[2] T. Nicholas and J.R. Zuiker, On the use of the goodman diagram for high cycle fatigue design, International Journal of Fracture $\mathbf{8 0}$ (1996), 219-235.

[3] B.A. Cowles, High cycle fatigue in aircraft gas turbines - an industry perspective, International Journal of Fracture 80 (1996), $147-163$.

[4] B. Garrison, Foreword, High Cycle Fatigue Science and Technology Program 2000 Annual Report, February 2001

[5] M.H. Shen, Development of a Free Layer Damper Using Hard Coatings, Proceedings of the 7th National Turbine Engine High Cycle Fatigue Conference, May 2002.

[6] J.B. Lazan, Energy Dissipation Mechanisms in Structures, with Particular Reference to Material Damping, Proceedings of the Colloquium on Structural Damping at ASME Annual Meeting, ASME, New York, 1959, 2-34

[7] E.E. Ungar, Damping Materials, Encyclopedia of Vibration, Academic Press, San Diego CA, 2001, 327-331.

[8] A. Baz, Active Damping, Encyclopedia of Vibration, Academic Press, San Diego CA, 2001, 351-364.

[9] J.B. Lazan, Damping of Materials and Members in Structural Mechanics, Pergamon Press, New York, 1968.

[10] A.D. Nashif, D.G. Jones and J.P. Henderson, Vibration Damping, John Wiley \& Sons, New York, 1985.

[11] J. Green and S. Patsias, A Preliminary Approach for the Modeling of a Hard Damping Coating Using Friction Elements, Proceedings of the 7th National Turbine Engine High Cycle Fatigue Conference, May 2002.

[12] M. Shipton and S. Patsias, Hard Damping Coatings: Internal Friction as the Damping Mechanism, Proceedings of the 8th National Turbine Engine High Cycle Fatigue Conference, April 2003.

[13] S. Patsias and R. Williams, Hard Damping Coatings: Material Properties and F.E. Prediction Methods, Proceedings of the 8th National Turbine Engine High Cycle Fatigue Conference, April 2003.

[14] P.J. Torvik, S. Patsias and G.R. Tomlinson, Characterizing the Behavior of Hard Coatings: Comparisons from Two Methodologies, Proceedings of the 7th National Turbine Engine High Cycle Fatigue Conference, May 2002.

[15] S. Patsias, G.R. Tomlinson and M.A. Jones, Initial Studies into Hard Coatings for Fan Blade Damping, Proceedings of the 6th National Turbine Engine High Cycle Fatigue Conference, March 2001.

[16] F.T. Ivansic, The Effect of a Hard Coating on the Damping and Fatigue Life of Titanium, Master's Thesis, AFIT/GAE/ENY/03-12, Department of Aeronautics and Astronautics, Air Force Institute of Technology (AU), Wright-Patterson AFB OH, March 2003.

[17] R.D. Cook, Concepts and Applications of Finite Element Analysis, (4th ed.), John Wiley \& Sons, New York, 2002.

[18] A. Leissa, Vibration of Plates, Washington, D. C., GPO, 1969.

[19] L. Meirovitch, Elements of Vibration Analysis, McGraw-Hill, Boston MA, 1986. 

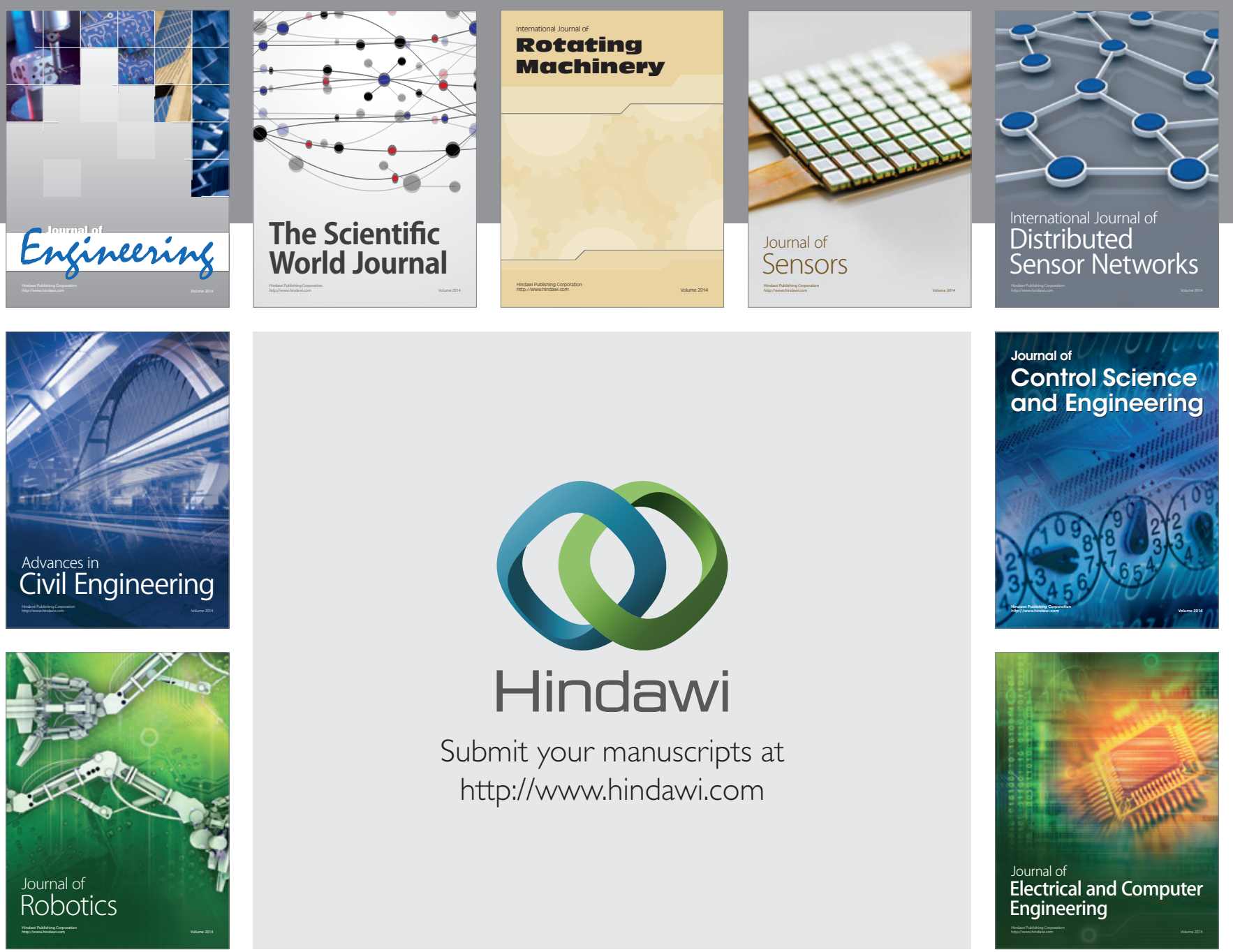

Submit your manuscripts at

http://www.hindawi.com
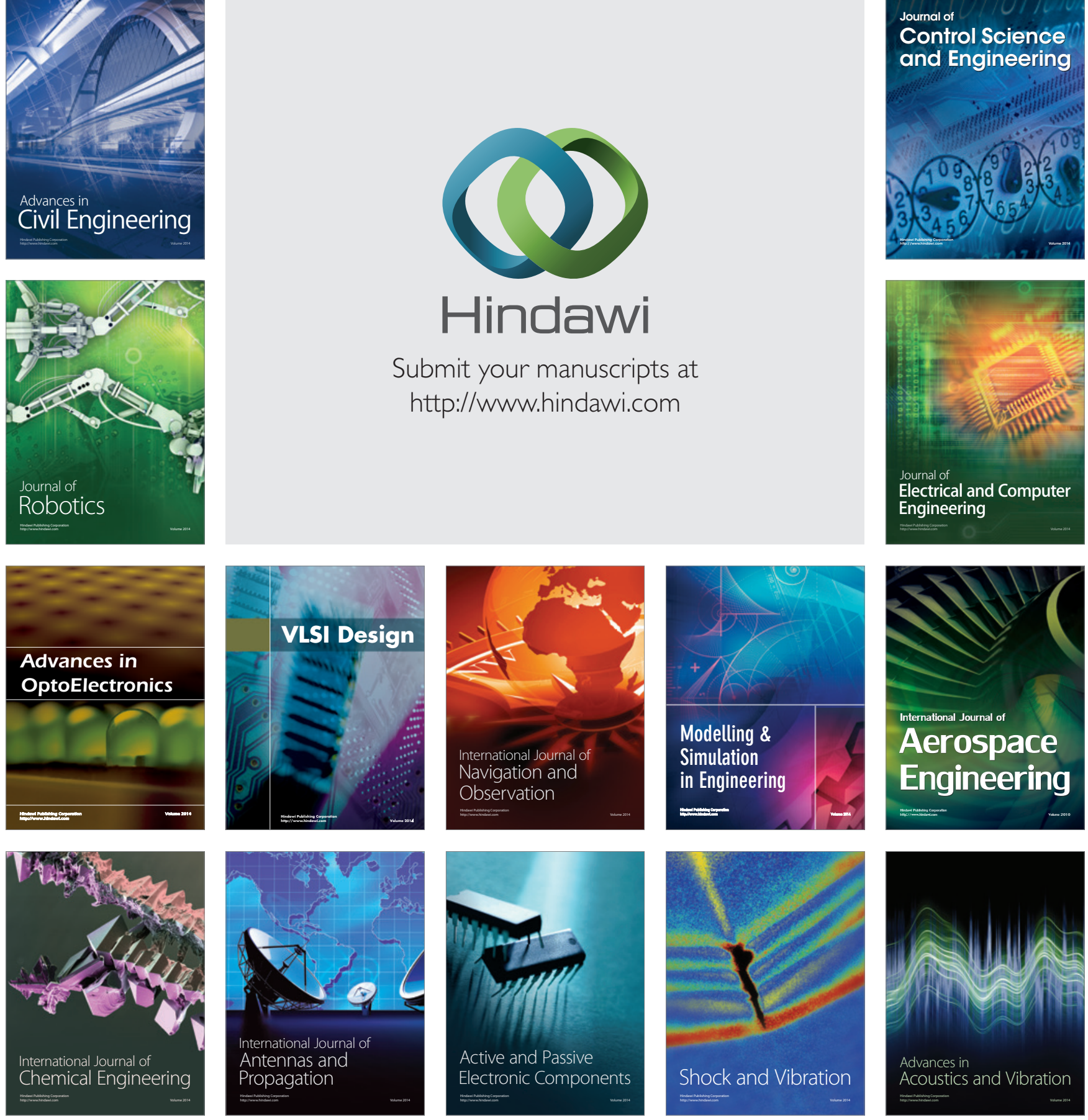